\title{
Muruy Maşrapasındaki Runik Yazı Üzerinde Yeni Bir Okuma ve Anlamlandırma
}

\section{A New Reading and Interpretation of the Runic Writing on the Muruy Vessel}

\author{
Erhan Aydın \\ Prof. Dr., İnönü Üniversitesi \\ Fen-Edebiyat Fakültesi Türk Dili ve Edebiyatı Bölümü, Malatya/Türkiye \\ e-posta ayerhan@gmail.com \\ orcid 0000-0003-4795-7320 \\ doi $\quad 10.54316 /$ dilarastirmalari.1019188
}

Atıf

Citation

Aydın, Erhan (2021). Muruy Maşrapasındaki Runik Yazı Üzerinde Yeni Bir Okuma ve Anlamlandırma.

Dil Araştırmaları, 29: 19-30.

\section{Başvuru \\ Submitted \\ 04.11.2021 \\ Revizyon \\ Revised \\ 08.11.2021 \\ Kabul \\ Accepted \\ 09.11 .2021 \\ Çevrimiçi Yayın \\ Published Online \\ 30.11 .2021}

\section{Öz}

Türklerin bilinen en eski yazılı belgeleri Türk runik harfleriyle yazılmış metinlerdir. Bu metinlerin bir bölümü hatıra taşı, mezar taşı ve kayalara; bir bölümü ise günlük hayatta da kullanılabilen eşyalar üzerine yazılmıştır. Bugün Türk runik harfleriyle yazılmış, beş yüzün üzerinde metin bulunmaktadır. Bu metinler ile ilgili yeni çalışmalarla, bilinen okuma ve anlamlandırma sorunlarına yeni öneriler getirilmektedir.

$\mathrm{Bu}$ makalede, 1970'li yıllardan beri bilinen, ancak 2008 yılında yayımlanan ilk çalışmaya kadar adından pek de söz edilmeyen iki maşrapa üzerinde durulacaktır. "Muruy maşrapaları" adıyla bilinen bu iki maşrapanın ikincisinde yer alan Türk runik harfli metin üzerinde yeni bir okuma ve anlamlandırma dikkatlere sunulacaktır. Makalede önce iki maşrapa hakkında bilgi verilecek, ardından Türk runik harfli metnin okunuşu ve anlamlandırılması ile ilgili önceki görüşlere değinilecektir. Makalenin üçüncü bölümünde ise, ikinci maşrapadaki Türk runik harfli metin ile ilgili yeni bir okuma ve anlamlandırma verilecek, bu okuyuş ve anlamlandırma ile ilgili gerekçeler gösterilecektir. Son bölümde ise maşrapadaki metin ile öteki maşrapanın altında bulunan damgadan hareket edilerek yazılmış olabileceği coğrafya üzerinde tartışılacak ve hangi bölgeye dâhil edilmesi gerektiği konusunda da görüş bildirilecektir. Anahtar Kelimeler: Eski Türkçe, Eski Türk Yazıtları, Güney Sibirya Yazıtları, Uygur Kağanlığı, Muruy Maşrapaları

\section{ABSTRACT}

The oldest known documents of the Turks are the texts written in Turkic runic letters. Some of those texts were craved on memory stones, tombstones, and rocks, while some of them were craved on the tools that could be used in daily life. Today there are over 500 texts written in Turkic runic letters. New studies appear about those texts, making new suggestions on the known reading and interpreting issues. 
This article will focus on two vessels which are known since 1970s but rarely mentioned until the first work published in 2008. A new reading and interpretation on the second of two vessels known as "Muruy Vessels" will be presented. On the article, primarily, the information about two vessels will be given, then former opinions on reading and interpretation of the text will be mentioned. On the third part of the article, a new reading and interpretation about the text in Turkic runic letters on the second vessel will be given. Also the reasons for that reading and the interpretation will be given. On the last part of the article, the area where it has been written will be discussed and opinions will be given as to which region they should be included based on the text on the second vessel and the mark under the other vessel.

Keywords: Old Turkic, The Old Turkic Inscriptions, Southern Siberian Turkic Inscriptions, Uyghur Khanate, Muruy Vessels

Bu makale, 75. yaş günü dolaylslyla değerli hocam Prof. Dr. Osman Fikri Sertkaya'ya ithaf edilmiştir.

\section{Giriş}

Türklerin ilk yazılı belgeleri eski Türk yazıtlarının yazılmasında kullanılan ve malzemelerin çeşitliliği göz önüne alındığında pek işlek olduğu anlaşılan Türk runik alfabesi, yalnızca dikili taşlara veya kayalara değil, gündelik hayatta kullanılan türlü eşyalar üzerine de yazılmıştır. Gündelik hayatta kullanılan eşyaların başında ise kuşkusuz maşrapalar gelmektedir. Maşrapaların, özellikle altlarına yazılan metinler dikkati çekse de bunların altın veya gümüş gibi değerli madenlerden yapılmış olması, kişinin mal varlığını göstermesi bakımından da değer kazanmaktadır. Özellikle Dağlık Altay ve Yenisey bölgesinde, maşrapalar üzerine yazılmış metinlerin ele geçmesi, Türklerin yazıya verdiği değeri göstermesinin yanında, halkın okuma yazma düzeyini göstermesi açısından kuşkusuz önemlidir.

Bu makalede, 1970'li yıllarda bulunduğu bilinen ancak 2008 yılında ilk kez bahsedilen makaleye kadar adından pek de söz edilmeyen Muruy maşrapaları hakkında bilgi verildikten sonra ikinci maşrapada yer alan Türk runik harfli metin üzerinde yeni bir okuma ve anlamlandırma dikkatlere sunulacaktır. Makalenin ilk bölümünde maşrapalarla ilgili eldeki bilgiler derlenecek, ikinci bölümde Türk runik harfli metnin okunuşu ve anlamlandırılması ile ilgili önceki görüşler değerlendirilecektir. Makalenin asıl bölümünde ise yeni bir okuma ve anlamlandırma sunulacak ve bu okuyuş ve anlamlandırma ile ilgili gerekçeler gösterilecektir.

\section{Muruy Maşrapaları}

2003 y1lında Rusya Federasyonu'na bağlı Irkutsk kentindeki Endüstriyel ve Sivil İnşaat Enstitüsünün restoratörü V. I. Malyuşenko, tanınmak istemeyen bir bayandan iki gümüş maşrapa satın alır. Bu iki maşrapanın, bayanın babasına ait olduğuna dair bilgi bulunmaktadır. Maşrapanın bulunuşu ile ilgili öykü şöyledir: Baba, Angara Irmağ 1 ve Bratsk yapay gölünde bir balıkçı teknesinde uzun süre kaptan olarak çalışır. Balıkçı 
teknesi, Muruy Adası'na demirlediğinde, kumlu plajda altı gümüş maşrapa bulur. Bayanın belirttiğine göre, ailesi defalarca yaşadığ 1 yeri değiştirmek zorunda kaldığ için, altı maşrapadan dördü kaybolmuştur. Kalan iki maşrapa ise hâlihazırda V. I. Malyuşenko’nun özel koleksiyonunda bulunmaktadır. Eldeki her iki maşrapa, üretim teknolojisi, boyutu ve tasarım özellikleri bakımından birbirine epeyce benzemektedir. Gümüşten yapılmış, geniş yuvarlak gövdeli, kısa geniş boyunlu, üst kenarı hafifçe bükülmüş, halka biçimli kulplara sahiptir. Maşrapaların altlarında dört adet damga bulunmakta olup ikincisinin altında bir runik metin ve bir daire içinde iki dağ keçisi figürü yer almaktadır. Maşrapanın ortasında ise, kesin bir görüntü oluşturmayan çok sayıda çizikler bulunmaktadır (Nikolayev ve Kubarev ve Kustov 2008: 175) ve (Kubarev 2015: 55-56).

Gleb V. Kubarev'in bölge ile ilgili verdiği bilgiler de ilgi çekicidir. Bratsk yapay göl yatağının su basmasından önce Muruy Adası, Irkutsk’tan Bratsk'a kadar Angara Irmağı'nın yatağındaki en büyük adalardan biriydi. Bu yer, Irkutsk oblastına bağlı UstUda yakınlarında, Irkutsk'tan 270 km kadar kuzeyde, Angara Irmağı'nın orta kesimlerinde bulunmaktadır. Şu anda ada, yaklaşık $1 \mathrm{~km}$ uzunluğunda ve $500 \mathrm{~m}$ genişliğinde, neredeyse bitki örtüsü olmayan bir arazi alanıdır (Kubarev 2015: 55-56). Ayrıca bu arazide birçok arkeolojik buluntuyla birlikte, bir çukurda bir at kafatasının ele geçtiği bilgisi de bulunmaktadır. (Nikolayev ve Kubarev ve Kustov 2008: 175).

Kubarev, bu altı gümüş maşrapanın aynı yerde bulunmuş olmasını, aynı kişinin kullanımından çok, esasen belki bir ganimet sonucunda elde edilmiş olabileceğini, ardından da sahibi ile birlikte gömülmüş olması gerektiğini ve altında damga bulunan maşrapadan hareket edildiğinde ise, sekiz veya dokuzuncu yüzyıla tarihlenebileceğini düşünmektedir (2015: 60).

İki gümüş maşrapanın fiziksel durumu ile ilgili şu bilgiler verilebilir: 1. maşrapa gümüşten yapılmış olup ağırlığı 219.5 gr'dır. Maşrapanın yüksekliği $10.5 \mathrm{~cm}$, gövde boyunca genişliği $10.5 \mathrm{~cm}$ kadardır. Geniş yuvarlak gövdeli, kısa geniş boyunlu, alçak tabanlı ve dikey olarak düzenlenmiş halka biçiminde kulpa sahiptir. Kulpun halkası, dört perçinle kabın gövdesine yapıştırılmıştır. Kulpun halkasında boncuk biçimli bir kabartma da bulunmaktadır. Maşrapanın altında ise, dört adet damgaya benzeyen işaretin dışında, herhangi bir harf veya yazı bulunmamaktadır (Nikolayev ve Kubarev ve Kustov 2008: 175).

2. maşrapa da gümüşten yapılmış olup ağırlığı 122.1 gr'dır. Geniş yuvarlak gövdeli, uzun boyunlu, alçak tabanlı ve dikey olarak yerleştirilmiş kabartma halka biçimli bir kulpu bulunmaktadır. Maşrapanın altında ise Türk runik harfli bir metin ve daire şeklinde dağ keçisi motiflerinin ağırlıkta olduğu damga benzeri şekillerle kaplıdır (Nikolayev ve Kubarev ve Kustov 2008: 175).

Nikolayev, Kubarev ve Kustov’un bu iki maşrapayla ilgili verdiği bilgi, ilk olması bakımından kuşkusuz değerlidir. Yazarların asıl sormak istediği ise, dördünün kaybolduğu bilgisi bulunan toplam altı maşrapanın gündelik hayatta kullanılıp kullanılmadığı ya da askerî seferlerden elde edilen ganimet olup olmadığı ve en önemlisi Türklerin Moğolistan merkezli kurduğu kağanlık mensupları tarafindan Sibirya’ya getirilip getirilmediğidir. İlk bilgileri veren araştırmacılar, maşrapaların II. Türk Kağanlığı döneminden Bilge Kağan'ın kağanlık zamanına ait olabileceği 
kanaatini taşımaktadır (Nikolayev ve Kubarev ve Kustov 2008: 181-182). Ancak aşağıda da belirtileceği üzere, Uygur Kağanlı̆̆ı'nın yazıtlarında da dağ keçisi simgelenen damganın kullanılmış olması, Bilge Kağan döneminden çok, Uygur Kağanlığ dönemine yerleştirilmesini daha olası kılmaktadır.

\section{Maşrapalara Değinmeler ve İkinci Maşrapadaki Metnin Önceki Okuma ve Anlamlandırmaları}

Yukarıda da ifade edildiği üzere, maşrapalarla ilgili ilk bilgi S. V. Nikolayev, G. V. Kubarev ve M. S. Kustov tarafindan 2008 yılında yayımlanan makalede verilmiştir. Dolayısıyla ilk bilgiler bu makaleden ve G. V. Kubarev'in 2015 yılında yayımlanan kitap bölümünden elde edilebilmektedir. Her iki yayında da Türk runik harfli metnin varlı̆̆ından söz edilmiş, ancak ayrıntıya girilmemiştir.

Kubarev, 2015 y1linda yayımlanan "A Runic Inscription on a Silver Vessel from the Bratsk Reservoir" başlıklı kitap bölümünde, ikinci maşrapanın altında bulunan yazıyı birkaç akademisyene gönderdiğini, ancak tatmin edici bir şekilde okunamadığını ifade eder ve Marcel Erdal'ın harf teşhislerini şöyle verir:

: $z / t^{2} b 1 / s^{1} k^{2} m n^{2} p s^{2} U k r^{2} m\left(y^{2}\right) / k^{2} U(?): d^{2}(?) d^{2}$ ? $\eta^{2} s 1$ ? $t 1$ ? yl $m c ̧ m r^{2} c ̧ / s^{2}$ $U k I: s^{2} r^{2} s^{2} r^{2} s^{2} U k z p s^{2} U k r^{2} m y^{2} U$ (Kubarev 2015: 61).

Dolayısıyla, ikinci maşrapadaki Türk runik harfli metindeki harflerin ilk transliterasyonu Marcel Erdal tarafindan yapılmış olmaktadır.

Maşrapadaki Türk runik harfli metin hakkındaki ilk okuma denemelerinden biri Napil Bazılhan'a aittir. Bazılhan'ın okuyuşu ve Kazak Türkçesine aktarımı şöyledir:

1. Ser ser seküzip sekürmeyü “серең-серең секіртіп (жорғалатып)", секірермін (шауып келермін) = Atlayacağım (sürüneceğim), atlayacağım."

2. Az kök minip sekürmeÿ̈ "Аз көк (атты) мініп, секірермін (шауып келермін) = Biraz boz (ata) binerim ve zıplarım (gelirim)."

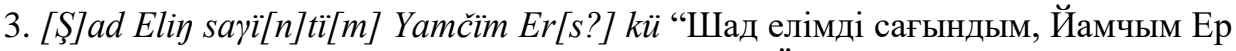
[?] атақты. = Mutlu ülkemi özlüyorum, Yamçım Er [?] Ünlü.” (Bazılhan 2015: 53).

Takashi Ôsawa'nın, 28-30 Kasım 2016'da Novosibirsk'te düzenlenen "International scientific workshop Altai among the Eurasian antiquities" başliklı sempozyuma sunduğu bildirisinde verdiği transkripsiyon ve İngilizce çevirisi şöyledir:

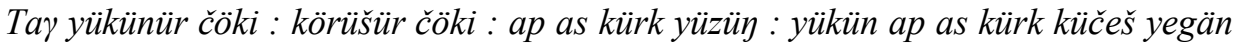
saqulayï : $a$ "They worship the mountain kneeling down and meet face to face it kneeling down! Don't $\mathrm{fl}$ ay the fur of the precious ermine, please! Don't make them compete with one another in forcibly seizing precious ermine! Yegän! Please watch over, oh! = Diz çökmüş dağa tapıyorlar ve diz çökmüş dağla yüz yüze buluşuyorlar! Değerli ermin kürkünü uçurmayın lütfen! Değerli erminleri zorla ele geçirmek için birbirleriyle rekabet etmelerini sağlama! Yegän! Lütfen izleyin, oh!” (Ôsawa 2016: 57$58)$. 
Ôsawa, damgalardan hareket ederek maşrapaları 747-759 yılları arasına tarihlendirir ve Uygur Kağanlığı dönemine denk gelen Yenisey Kırgızlarına ait olduğunu belirtir. Ayrıca maşrapada, açıkça seçilemese de Çince bo (博) karakterinin bulunduğunu öne sürer ve tümüyle tahmin ve okumasından elde ettiği sonuçtan hareket ederek Yegen adlı kimsenin Yenisey Kırgızları döneminde Muruy bölgesinin yöneticisi olduğunu belirtir (2016: 58).

Anılan sempozyum bildirilerinin yayımlanmasının ardından, bölgede faaliyet gösteren internet sayfaları ile sempozyumu düzenleyen Institut Arheologii i Etnografii Sibirskogo Otdeleniya Rossiyskoy Akademii Nauk, bu okuma ve anlamlandirma hakkında haber yapar: e-baikal ve e-old.archaeology

Vladimir V. Tişin ve Nikolay N. Seregin'in yeni bir okuma ve anlamlandırma önerisi getirdiği Biyreg yazıtında yer alan harf biçimlerinden birinin Muruy maşrapasında, Marcel Erdal'ca $H_{m}$ olarak belirlenen harfe benzerliğinden dolayı adı anılır ve maşrapanın henüz iyi bir okuma ve anlamlandırmasının yapılmadığı belirtilir (2017: 188).

2019 yılında Aleksey E. Rogojinskiy ve Dmitry V. Çeremisin, Altay ve Semireçye bölgelerinde elde edilen kayaüstü tasvirlerdeki damgalarla Türk runik harfli yazıtlarda bulunan damgaları karşılaşıırdığı yazılarında, Muruy maşrapalarının birincisindeki damgayı Şine Usu ve Karı Çor Tegin yazıtlarındaki damgalarla karşılaştırır ve maşrapadaki damgayı verir (2019: 51). Bu yazılarında ele alınan konu, bir başka yazılarında da aynıyla işlenir (2020: 301).

2020 yllında Vladimir V. Tişin, Aleksey E. Rogojinskiy ve Nikolay N. Seregin tarafindan "Vostok (Oriens)" dergisinde yayımlanan makalede, önce maşrapalarla ilgili yapılan yayınlardan söz edilir, ardından maşrapaların fiziksel özellikleri ile ilgili bilgi verilir. Makalenin yazarları, Uygur Kağanlığı'nın Moyan Çor Kağan dönemine tarihlenebileceğini düşünür (2020: 191-192 ve 196-197). Makalenin geri kalan bölümü ise Türk runik harfli metnin okunmasına ayrılmıştır. Metnin transkripsiyonu ve Rusçaya çevirisi şöyledir:

$<\ldots>t(a) \gamma(a) y(i) m(i) n^{2}(e) r(i) \eta_{\underline{u} k i}^{\ddot{2}}: \ddot{u} r(\ddot{u}) \eta(e) r(i) \eta_{\underline{u} k i}:(a) p \operatorname{sök}(\ddot{u}) r m(\ddot{a}) y \ddot{u}:(e) t$ :

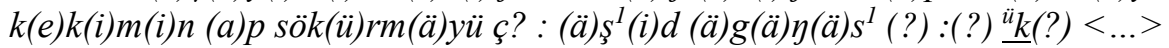

“<..> ...ппри помощи] дяди [по материнской линии] моего, [тех, кто относится к] раздраженным (= пренебрегающим, отвергающим), белых (= светлых / чистых, благородных) [(из) тех, кто относится к] раздраженным (= пренебрегающим, отвергающим), ни в коем случае не заставляя преклонить колени, (об)устрой (= организуй, приведи в порядок), гневом (или 'желанием мести'?) моим [одержимый,] ни в коем случае [их] не заставляя преклонить колени, услышь, Эгенгес(?) ! ... <..>”

“<..> ... [yardımıyla] amcam [anne tarafindan], [ait olanlar] sinirli (= ihmalkâr, reddedici), beyaz (= parlak / saf, asil) [(dan ) ait olanlar] benim [sahip olduğum] hiçbir durumda [onların] sizi diz çökmeye, duymaya zorlamadan, Egenges(?)! ... <..>" (2020: 199). 
$\mathrm{Bu}$ okuma ve anlamlandırma ile ilgili notlarda ise, okunan sözcüklerin sonraki dönem Türkçe metinlerde geçen biçimleri verilir. Örneğin tagay 'dayı' sözcüğü yazıtlar dönemi Türkçesinde ele geçmediği için, özellikle Kâşgarlı Mahmud’un Dîvânu Lûgâti't-Türk'ündeki örnek tanık gösterilir. Okumada yer alan öteki sözcükler de eski Türkçe sözcük farz edilerek anlam verilir. Örneğin erinüki bunlardan biridir. Yine ap ... ap edatının varlığının türlü sözlüklerle açıklanmaya çalışılması ve kekimin ve ägänäs okumalarının herhangi bir anlam ifade etmemesi, tümüyle zorlamadan kaynaklanmaktadır (2020: 199-200).

\section{Yeni Bir Okuma ve Anlamlandırma}

Altında Türk runik harfleriyle yazılmış bir metin bulunan ikinci maşrapadaki harfleri belirlemek üzere iki farklı çizimin yapıldığı anlaşılmaktadır. Bunlardan birincisi Kubarev'in verdiği çizim (2015: 57 ve 60), ikincisi ise Tişin, Rogojinskiy ve Seregin'in verdiği fotoğraf ve çizimdir (2020: Tablo 4 ve 5). Marcel Erdal'ın metindeki harflerle ilgili teşhisleri, Kubarev'in çizimlerine dayanmakta olup harflerle ilgili verdiği ses değerlerini başarılı olarak değerlendirmek gerekir. Napil Bazılhan da Kubarev'in gönderdiği çizimden yararlandığını ifade eder (2015: 53). Bu satırların yazarı ise, esasen Kubarev'in çiziminden yararlanmış, bunun yanında Tişin, Rogojinskiy ve Seregin'in verdiği çizimle de karşılaştırmıştır. Harflerin tam teşhisinde Kubarev'in verdiği çizim, ötekine göre daha başarılıdır.

Yeni bir okuma ve anlamlandırma şöyledir:

Transliterasyon:

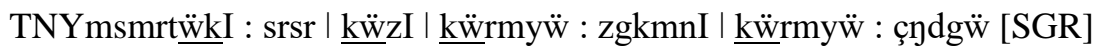

Transkripsiyon:

Tanyım(?) semrit<d>öki esürser közi körmeyü ezüg kimni körmeyü içiy edgü sagır

Türkiye Türkçesine aktarımı:

Tay(lar)1m(1n)(?) beslediği sarhoş olursa gözü (önünü) görmeyene kadar sahtekâr kişiyi görmeyene kadar için! (Bu) İyi maşrapa(dır).

Metnin, fotoğrafta kararmış olarak görünen, aşınmış bölümün bulunduğu yerin hemen solundan başlıyor olması gerekir. 


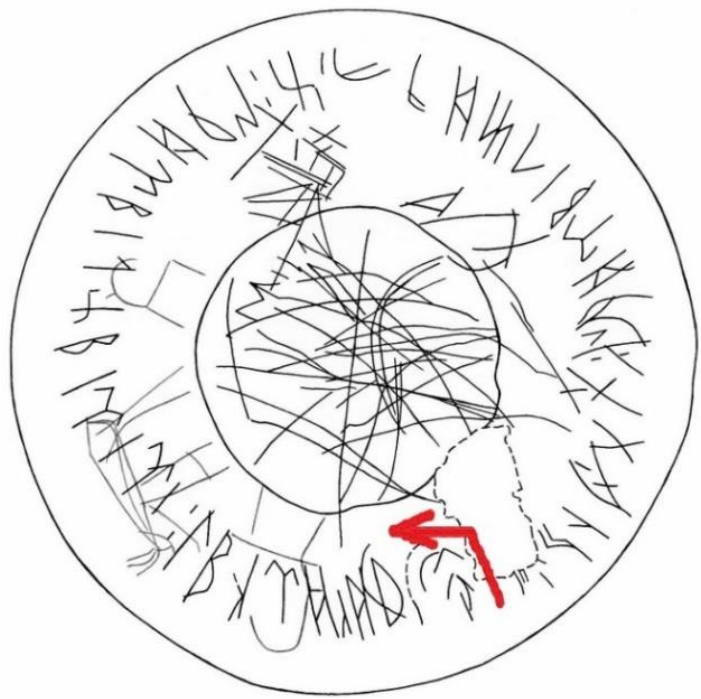

Çizim: Kubarev 2015: 60

Tanyım: Sözcüğün yazımı tuhaftır. 'at yavrusu' anlamındaki tay sözcügü, eski Türk yazıtlarında bir kez y sesi ile tay (Küli Çor yazıtı doğu 3. satır) ve üç kez de tañ (Hemçik-Çırgakı (E 41) yazıtı 2, 5 ve 11. satır) olmak üzere toplam dört kez tespit edilmiştir. Hemçik-Çırgakı yazıtındaki yazımın doğru olması gerekir. Ancak maşrapada tanyım yazılmış olmalıdır. $\tilde{n}$ sesinin, $\tilde{n}$ ile değil de $n y$ biçiminde iki harf ile yazımının en ünlü örneği, Toñukuk adının Bilge Kağan yazıtı güney yüzü 14. satırdaki tonyukuk yazımıdır (Aydın 2017: 99). Dolayısıyla tañ sözcüğü burada $n$ ve $y$ harfleri ile yazılmış olmalıdır.

Semrit $<d>$ öki: Eski Türk yazıtlarında semri-/semrit- fiili tespit edilmemiş, ancak Tonyukuk yazıtında iki kez (1. taş batı yüzü 5 ve 6 . satır) aynı kökenli semiz sözcüğü ele geçmiştir. Ayrıca yine Türk runik harfli Irk Bitig'in 16. ırkında semrit- fiili bulunmaktadır: Toruk at semriti yérin öpen yügürü barmış "Zayıf at kendisini semirten yeri düşünüp koşarak (o yere doğru) gitmiş." (Yıldırım 2017: 36). Ayrıca krş. (ED 830a).

Esürser: 'Sarhoş olmak' anlamındaki şart ekli esür- fiili, eski Türk yazıtlarında tespit edilmemiştir. Büyük kağanlık ve beylik yazıtları ile, ölen kişi adına dikilmiş mezar anıtlarında zaten 'sarhoş olmak' anlamında bir fiilin geçmiş olması beklenemez. Ancak Eski Uygur Türkçesi döneminden itibaren sıkça kullanılan ve Türkçenin her döneminde iyi bilinen bir fiil olduğu anlaşılmaktadır (ED 251a). Metin bir maşrapanın altında yazılı olduğuna göre, 'sarhoş olmak' anlamındaki esür- fiilinin geçmiş olması yadırganmamalıdır.

Körmeyü: Belki de metnin en açık ve anlaşılması kolay sözcüğü olup cümle öğesi olarak zarf göreviyle kullanılmıştır. Ünlü zarf-fiili eki -U'nun her iki sözcüğe kattığı anlam “-e (kadar)" olmalıdır. 
Ezüg: Belirtme hâli ekli kimni yapısının önünde bulunan bu sözcük ezüg olarak okundu. 'Yalan, hata, yalancı, hatalı, sahtekâr' gibi bir anlamda kullanılan sözcük, eski Türk yazıtları döneminde tespit edilmemiştir. Ancak, Eski Uygur Türkçesi döneminden itibaren bilinen ve kullanılan bir sözcük olduğu anlaşılmaktadır (ED 285a) ve (Hamilton 1998: 172).

İçiฑ: Metinde okunması güç yerlerden biridir. Çünkü ç harfinin bulunduğu yerde birçok dikey çizgi, birbirine karışmıştır. Eldeki malzeme, maşrapa olduğuna göre içfiilinin geçmiş olması doğaldır. Çünkü gerek Yenisey gerekse Dağlık Altay'da ele geçen maşrapalarda $i c ̧$ - fiilinin geçtiği bilinmektedir. İç- fiilinin geçtiği öteki yazıtlar ve cümleler şöyledir:

Kopön Altın Küp II (E 82) yazıtı: < ..> altun $\operatorname{sagl<r>içi\eta ~"<\ldots >~altın~maşrapadan~}$ için!"' (Aydın 2019: 194).

Katanda (A 2): (i)ç(i)ク “içiniz". Bu maşrapa üzerinde çalışanlar, $l^{2} g^{2} c ̧ \eta$ biçimiyle transkripsiyon yapıp herhangi bir anlamlı okuma elde edememiştir. Ancak Osman F. Sertkaya ve Viktor Ya. Butanayev, maşrapada $(i) c ̧(i) \eta$ "içiniz!" yazılı olduğunu önerir (2011: 128). Böylelikle eski Türk yazıtlarında iç- fiili, iki kez bu iki maşrapada tespit edilmiş olmaktadır.

Edgü sagır: Metinde okunması güç yerlerden biridir. Tişin, Rogojinskiy ve Seregin'in hazırladığı ortak makalede yer alan fotoğrafta açıkça görüleceği üzere kararmış bölümden dolayı buradaki harfler seçilememekte, ancak harflerin üst veya alt ucu görünmektedir (2020: tablo 4, resim 5). Ayrıca Kubarev'in verdiği çizimde de bu kararmış yer, boş olarak işaretlenmiştir (2015: 60). Bu bölümde edgü okunan sözcügüun sonundaki harf, daha çok art damak ünsüzü $\eta$ 'ye benzese de edgü okumak daha açıklayıcı olacaktır. Ardında yer alan art ünlülü $s^{l}$ çok açıktır, ancak ardındaki bölümde hangi harflerin bulunduğunu bilmek mümkün değildir. Bu bölüm 'Maşrapa' anlamındaki sagır olarak okunabilir. Bu sözcük, yalnızca iki Yenisey yazıtında tespit edilmiş olup sözcüğün geçtiği yer ve cümleler şöyledir:

Kopön Altın Küp II (E 82): < ..> altun $\operatorname{sagl}_{l}<r>i c ̧ i \eta ~ “<\ldots>$ altın maşrapadan için!" (Aydin 2019: 194).

Kulplu Gümüş Maşrapa: Sagrımıs "bardağımız (maşrapamız)” (Aydın 2019: 242).

G. Clauson, sözcüğe 'maşrapa, kadeh' anlamını vermiş olsa da sözcüğün okunuşu konusunda, Dîvânu Lügâti 't-Türk'te 'şarabın konulduğu havan şeklinde konik bir kap' anlamıyla geçen sagrak örneğini tanık gösterir (ED 814b). Dolayısıyla, Yenisey yazıtlarında geçen iki örnek de Clauson'da yer almaz. Sagır sözcüğü, Eski Uygur Türkçesi metinlerini yayımlayanlardan A. von le Coq ve Klaus Röhrborn tarafindan sagar biçiminde verilmiş ise de Sertkaya ve Butanayev, sözcüğün asıl biçiminin Dîvânu Lügâti 't-Türk'teki sagır olduğunu belirtir. Ancak yazarlar, Kopön Altın Küp II (E 82)'deki örneği sagl olarak tespit ettiği için, sagır sözcüğünün farklı bir biçimi olduğunu öne sürer (2011: 123). Hâlbuki sözcük sonuna, yazımı unutulmuş bir $r$ harfi eklendiğinde zaten sagır elde edilebilmektedir (Aydın 2019: 194). Böylece, Yenisey yazıtlarından elde edilen iki tanık da sözcüğün sagar değil, sagır olduğuna işaret etmektedir. Kâşgarlı'nın verdiği sagrak biçiminin ise $+A K$ küçültme eki ile yapıldığı anlaşılmaktadır. Kâşgarlı Mahmud'un verdiği sagır 'koni şeklinde ve havana 
benzeyen, içine şarap vb. konulan kap' ve sagrak 'içmek için kullanılan çamçak ve kadeh' için bk. (Ercilasun ve Akkoyunlu 2015: 799).

Sagır sözcügünün kökeni ile ilgili ağırlıklı görüş, Farsçadan alındığı yönündedir (TMEN III: No. 1247). Ancak bu görüşte olanların, Yenisey yazıtlarındaki iki örneği gözden kaçırdığg anlaşılmaktadır. Güney Sibirya'da yaşayan eski Türk halklarının iyi bildiği bir sözcük olması dolayısıyla kökeninin, en azından Farsça olmayacağı öne sürülebilir.

İkinci maşrapanın altında bulunan Türk runik harfli metnin yazımı içinse şunlar söylenebilir: Harf karakterleri öteki Türk runik harfli metinlerle neredeyse aynıdır. Belki yalnızca $m$ harfinin biçiminin, hem Dağlık Altay hem de Yenisey bölgesindekilerden biraz farklı olduğunu eklemek gerekir. Yazımla ilgili bir başka önemli husus da ön $s^{2}($ ) harfine benzeyen dik bir çizginin sözcük ayırıcı olarak kullanılmış olmasıdır. Bu yazım da alışıldık bir noktalama işareti değildir. Kimni belirtme hâli ekli yapıda ise $I$ ünlüsü, $p$ harfine benzer şekilde ayna pozisyonunda yazılmıştır.

\section{Değerlendirme ve Sonuç}

Muruy maşrapaları adıyla bilinen ve toplam altı adetten dördünün kaybolması sonucunda, ancak bugün elde ikisinin kaldığ 1 belirtilen gümüş maşrapalardan birincisinin altında bir boy damgası, ikincisinde ise Türk runik harfli bir metin bulunmaktadır. Boy damgasının, II. Türk Kağanlığı'nın yönetici boyunun damgası olduğunu öne sürenler bulunsa da esasen Uygur Kağanlığı'nın yönetici boyu olan Yaglakar hanedanının damgası olduğu fikri daha uygun görünmektedir. Çünkü maşrapadaki damganın aynısı, Uygur Kağanlığı döneminin kağanlık yazıtı Şine Usu ile Çin'in eski başkenti Chang'an'de ele geçen ve Moyan Çor Kağan'ın torunu Karı Çor Tegin'in anısına hazırlanan iki dilli Türkçe-Çince mezar taşının en alt bölümündeki damga ile aynıdır. Dolayısıyla, Uygur Kağanlığı'nın Moyan Çor Kağan döneminde (747-759/760) kuzeye yapılan seferlerle, Güney Sibirya bölgesinin Uygur Kağanlı̆̆ı'na bağlandığını ve maşrapaya işlenen damga ile sahibinin bu yönetime mensup olduğunun ifadesinden başka bir şey olmaması gerekir.

İkinci maşrapanın altında ise Türk runik harfli bir metin bulunmaktadır. Maşrapanın altında çok fazla çiziklerin bulunması, okunması ve anlaşılmasını güçleştirdiği için, önceki okumaların bir bölümü, tümüyle tahmin olarak kalmıştır ve elde edilen sözcükler sanki başka bir dile aitmiş gibi bir izlenim edinilmesine neden olmuştur. İlk harf teşhisi denemesinin sahibi Marcel Erdal, herhangi bir okuma yapmamış olsa da harf teşhisleri başarılı sayılabilir. Ôsawa ve Bazılhan'ın okuyuşlarından, bilinen, anlamlı bir sözcük veya cümle elde etmek mümkün değildir. 2020 yılında Tişin, Rogojinskiy ve Seregin tarafından yapılan okuma, öncekilere göre daha başarılı gibi görünse de metinde farz edilen sözcüklerden hareket edilerek yeni bir çizim yapmaları sonucunda, sözcüklerin büyük bir bölümünü, Türkçede hiç kullanılmamış, tahmini sözcükler oluşturmaktadır.

İkutsk Oblastında bulunan Angara Irmağı civarında ele geçtiği için, maşrapalardaki damga ile runik metnin, Yenisey (Tuva ve Hakasya) yazıtları bölgesine 
mi yoksa Dağlık Altay yazıtları bölgesine mi dâhil edilmesi gerektiği, önemli bir sorundur. İrkutsk gibi oldukça kuzeyde bulunmuş olması, maşrapanın burada kullanıldığı ve metnin burada yazıldığı anlamına gelmemektedir. Uygur Kağanlığı'nın beyleri veya askerlerinin, Orta Moğolistan'daki asıl vatanlarından, Güney Sibirya'ya yapılan seferler marifetiyle bu bölgeye getirmiş olabileceğini düşünmek yerine, bu bölgede Uygur Kağanlığı'na bağlı olarak yaşayan, ancak zengin veya güçlü bir kimsenin ganimet yoluyla elde edilmiş ve ardından altına bir özlü söz yazdırılmış olabileceği daha anlamlı görünmektedir. Eğer gerçekten bu maşrapalar altı adet idiyse ve geri kalan dördünün de gümüşten yapılmış olabileceği düşünüldüğünde, bu maşrapaların sıradan insanların değil, zengin, nüfuzlu veya yönetici kesimden bir kimseye ait olabileceği konusunda epeyce fikir vermektedir.

\section{Kısaltmalar ve Kaynakça}

Aydin, Erhan (2017). Orhon Yazıtları, Köl Tegin, Bilge Kăgan, Tonyukuk, Ongi, Küli Çor. İstanbul: Bilge Kültür Sanat Yayınları.

AYdin, Erhan (2019). Sibirya'da Türk İzleri, Yenisey Yazıtları. İstanbul: Kronik Kitap.

BAZILHAN, Napil (2015). "Köne türik bitik jazulı keybir eskertkişter turalı". Til Jäne Kogam, 39/1: 43-57.

ÇEREMISIN, Dmitry V. ve Aleksey E. RogojinskiY (2020). "Rock art of the ancient Türks of the Russian Altai". Naskal'niye Letopisi Zolotoy Stepi ot Karatau do Altaya. (Edt: Esther Jacobson Tepfer; V. A. Novozhenov). Tom. 2. Almatı: Medeniyetterdi Jakındastıru Ortalıg1, 301-335.

ED: Clauson, Gerard (1972). An Etymological Dictionary of Pre-Thirteenth-Century Turkish. Oxford: Oxford University Press.

Ercilasun, Ahmet B. ve Ziyat AkKoyunlu (2015). Dîvânu Lugâti't-Türk. Ankara: Türk Dil Kurumu.

Hamilton, James R. (1998). Budacı İyi ve Kötü Kalpli Prens Masalının Uygurcası. Türkçeye çev.: Ece KorKuT ve İsmet BirKan. Ankara: Simurg.

Kubarev, Gleb V. (2015). "A Runic Inscription on a Silver Vessel from the Bratsk Reservoir". Interpreting the Turkic Runiform Sources and the Position of the Altaic Corpus (Edt: Irina Nevskaya; Marcel Erdal). Berlin: Klaus Schwarz Verlag, 55-63.

NikolayeV, V. S.; Kubarev Gleb V.; Kustov M. S. (2008). "Serebryaniye sosudı s ostrova Muruyskiy". İvestiya Laboratorii Drevnih Tehnologii, 6: 175-183.

ÔsawA, Takashi (2016). "New Interpretation of the old Turkic Inscription on the Silver Vessel from the Murui Region". Altay v Krugu Yevraziyskih Drevnostey, Tezisı dokladov mejdunarodnogo nauçnogo seminara (28-30 Noyabr 2016), Novosibirsk: Institut Arheologii i Etnografii Sibirskogo Otdeleniya Rossiyskoy Akademii Nauk, 57-58.

RogoJINSKIY, Aleksey E.; ÇEREMISIN Dmitry V. (2019). "Tamgi koçevnikov Tyurkskoy epohi na Altaye i v Semireç'ye (Opıt sopostavleniya i identifkatsii)". Arheologiya Etnografiya $i$ Antropologiya Yevrazii, 47/2: 48-59.

SertKAyA, Osman F.; ButAnAYev Viktor Ya. (2011). "Runik Yazılı Maşrapalar Üzerine (8. Hakasya'da Bulunan Runik Yazılı Gümüş Maşrapa". Ötüken'den İstanbul'a Türkçenin 1290. Yılı (720-2010) Sempozyumu. Bildiriler (Edt: Mehmet Ölmez; Erhan Aydın; Peter Zieme; Mustafa S. Kaçalin). İstanbul: İstanbul Büyükşehir Belediyesi Yayınları, 119-130.

Tişin, Vladimir V.; SEREGIN Nikolay N. (2017). "K voprosu o metodike proçteniya redkih znakov nekotorıh runiçeskih nadpisey Tsentral'noy Azii (Po materialam kompleksa Biyreg v Mongol'skom Altaye". Vestnik SPbGU. Vostokovedeniye i Afrikanistika, 9/2: 183-195.

Tişin, Vladimir V.; RogojInSKIY Aleksey E.; SEREgIN Nikolay N. (2020). "Tamgi i runiçeskaya nadpis' na dvuh sosudah s ostrova Muruyskiy na Angare”. Vostok (Oriens), 2020/1: 191-206.

TMEN: DOERFER, Gerhard (1967). Türkische und Mongolische Elemente im Neupersischen. Band: III. Wiesbaden: Franz Steiner Verlag. 
YILDIRIM, Fikret (2017). Irk Bitig ve Orhon Yazılı Metinlerin Dili. Ankara: Türk Dil Kurumu.

\section{Internet kaynakları:}

e-baikal = “Японец прочёл руны на древних кувшинах, найденных на берегу Ангары" https://www.baikal-daily.ru/news/16/236216/ (Erişim tarihi: 01.11.2021).

e-old.archaelogy = "Прочтены руны на серебряных кувшинах" http://old.archaeology.nsc.ru/ newsarcru/127 (Erişim tarihi: 01.11.2021).

\section{Ekler}
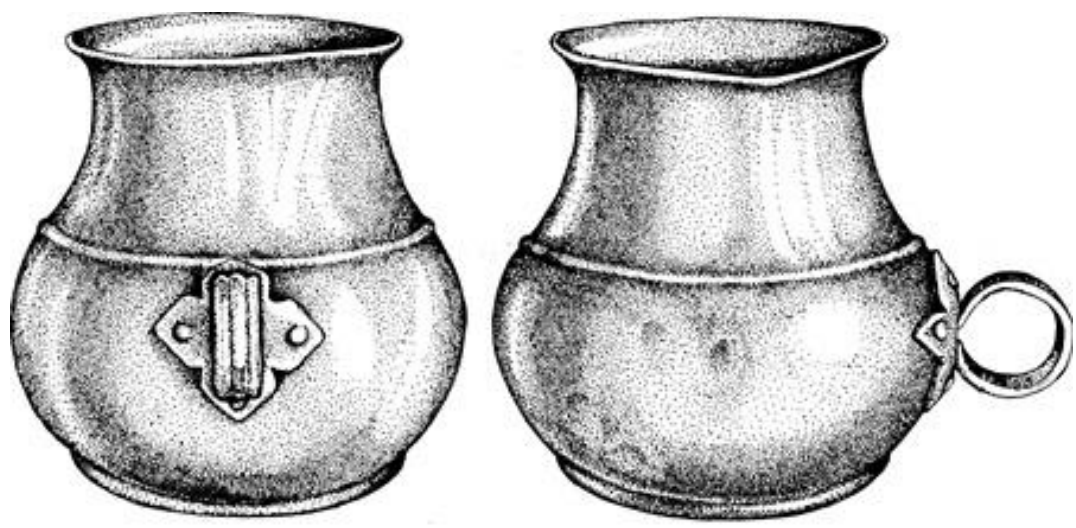

Çizim: Kubarev 2015: 57

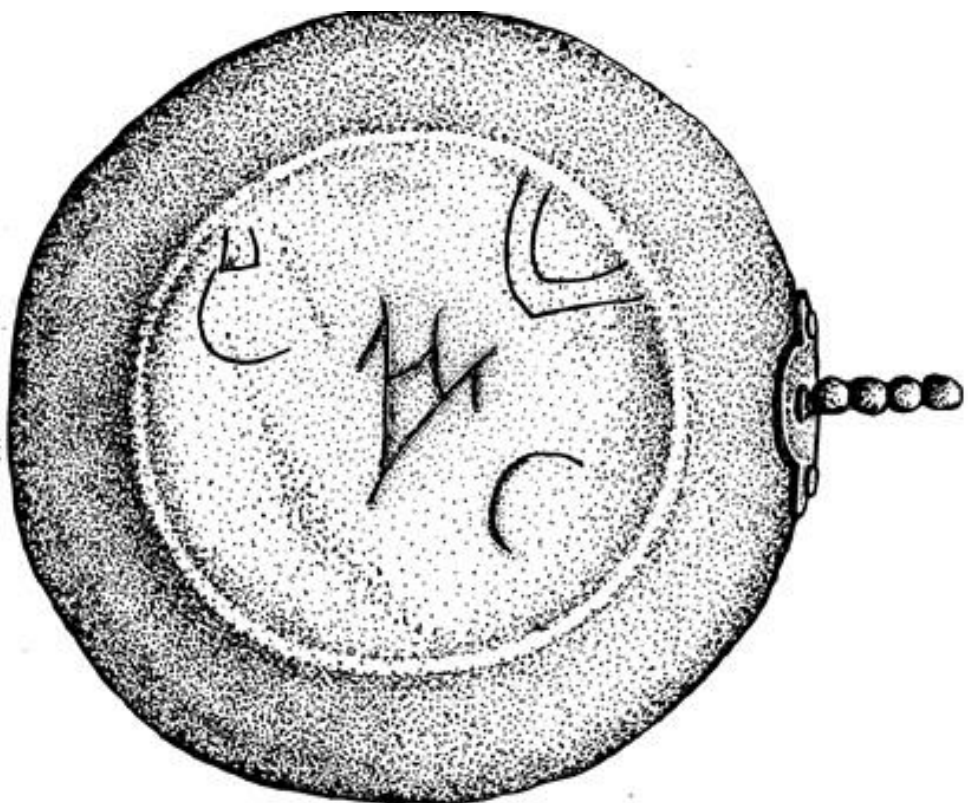

Birinci maşrapanın altı. Çizim: Kubarev 2015: 61 


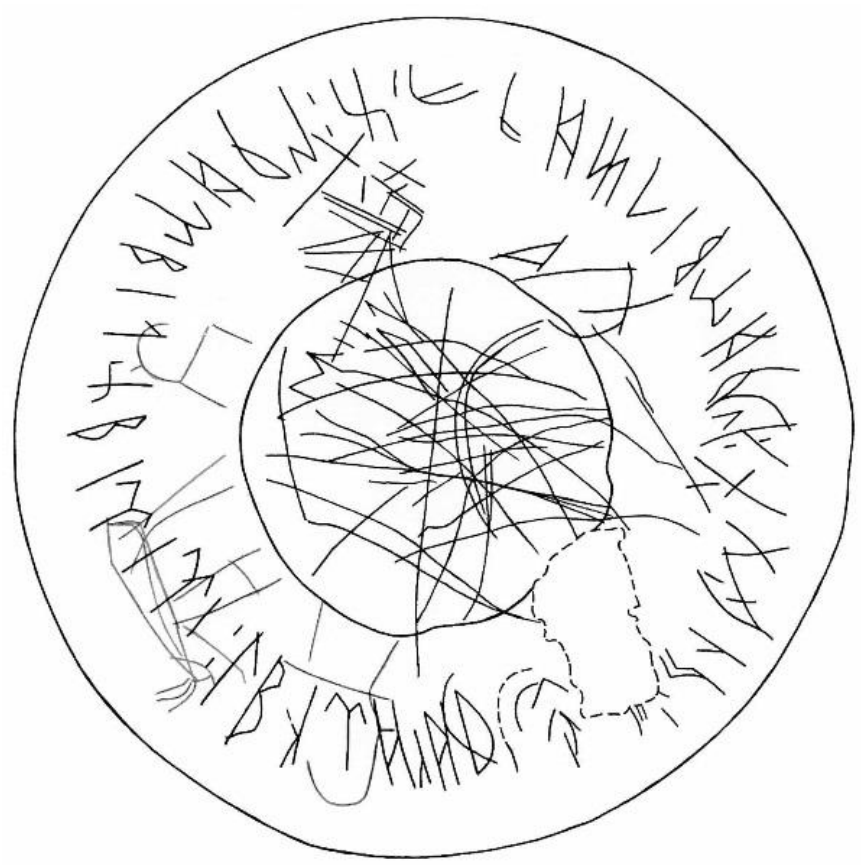

İkinci maşrapadaki metin. Çizim: Kubarev 2015: 60

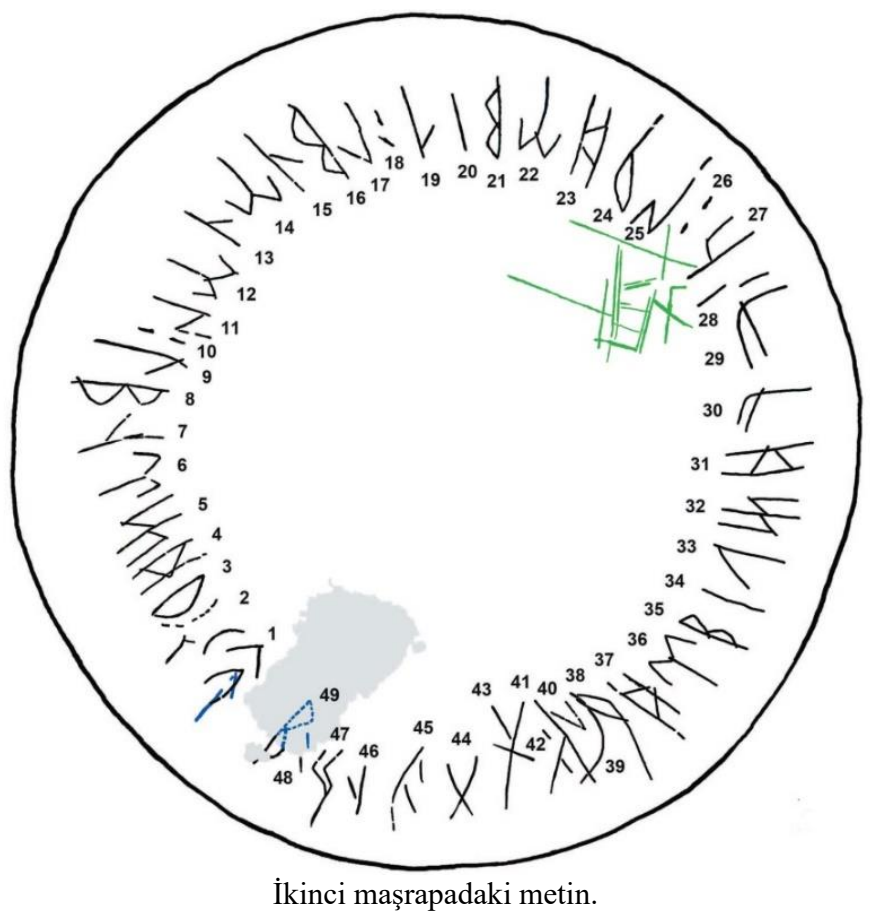

Çizim: Tişin ve Rogojinskiy ve Seregin 2020: Tablo 5 